\title{
PRODUÇÃO E QUALIDADE DE FRUTOS HÍBRIDOS DE MARACUJAZEIRO-AMARELO NO NORTE DO PARANÁ ${ }^{1}$
}

\author{
RICARDO SFEIR DE AGUIAR²,PAULO VICENTE CONTADOR ZACCHEO 3 , \\ NEUSA MARIA COLAUTO STENZEL ${ }^{4}$, TUMORU SERA ${ }^{5}$, \\ CARMEN SILVIA VIEIRA JANEIRO NEVES 6
}

RESUMO-Atualmente, encontram-se quatorze cultivares de maracujazeiro-amarelo no Registro Nacional de Cultivares do Ministério da Agricultura. É de grande importância o aprimoramento de trabalhos de melhoramento genético nessa cultura, para favorecer a disponibilização de novas cultivares adaptadas às regiões produtoras. Assim, o objetivo deste trabalho foi avaliar a produção e as características qualitativas dos frutos de treze híbridos de maracujazeiro-amarelo cultivados no norte do Paraná. As avaliações foram realizadas durante dois ciclos de produção da cultura, de abril a julho de 2009 e de janeiro a julho de 2010 , com coletas semanais dos frutos maduros. A produção foi determinada por meio da pesagem dos frutos colhidos e do número de frutos por planta. Para as características qualitativas, foram avaliados: massa, comprimento, diâmetro, relação entre comprimento e diâmetro dos frutos, espessura da casca, rendimento de polpa, teor de sólidos solúveis totais (SST), acidez total titulável (ATT) e relação SST/ATT. Os híbridos '66' e '65' apresentaram, respectivamente, maior produção e maior número de frutos no acumulado das duas safras. Os frutos do híbrido ' 72 ' destacaram-se no atendimento das características desejáveis de qualidade para o consumo in natura, enquanto o híbrido '69' apresentou caracteristicas importantes para a indústria de suco. Termos para indexação: Maracujá, Passiflora edulis Sims, características físico-químicas.

\section{YIELD AND QUALITY OF FRUITS OF HYBRIDS OF YELLOW PASSION FRUIT IN NORTHERN PARANÁ}

\begin{abstract}
Nowadays there are fourteen cultivars of yellow passion fruit on the National Register of Cultivars of the Brazilian Ministry of Agriculture. The improvement of plant breeding in this crop is of great importance to provide new cultivars adapted to the producing regions. Thus, the aim of this study was to evaluate the production and fruit quality of thirteen hybrids of yellow passion fruit plants grown in the northern Paraná. The evaluations were performed during two cycles of crop production from April to July 2009 and from January to July 2010 with weekly harvests of ripe fruits. The production was determined by weighing the total output and counting the number of fruits per plant. The evaluated quality characteristics of the fruits were: weight, length, diameter, diameter/length ratio, thickness, pulp yield, total soluble solids (TSS), total titratable acidity (TTA) and TSS/TTA ratio. Hybrids ' 66 ' and ' 65 ' respectively showed the highest yield and greatest number of fruits in the accumulated of the two crops. The fruits of the hybrid ' 72 ' stood out on desirable quality characteristics for fresh consumption, while the hybrid ' 69 ' showed important features for the juice industry.
\end{abstract}

Index terms: Passion fruit, Passiflora edulis Sims, physico-chemical, characteristics.

'(Trabalho 012-14). Recebido em: 14-01-2014. Aceito para publicação em: 02-07-2014.

${ }^{2}$ Eng. Agr. MSc. Doutorando do Programa de Pós graduação em Agronomia, Universidade Estadual de Londrina. E-mail: rsaguiar@ hotmail.com

${ }_{3}^{3}$ Eng. Agr. MSc. Doutorando do Programa de Pós graduação em Agronomia, Universidade Estadual de Londrina. E-mail; pvczaccheo@ yahoo.com.br

${ }^{4}$ Eng. Agr. Dr. Pesquisadora do Instituto Agronômico do Paraná. E-mail: nstenzel@iapar.br

${ }^{5}$ Eng. Agr. Dr. Pesquisador do Instituto Agronômico do Paraná. E-mail:tsera@iapar.br

${ }^{6}$ Eng. Agr. Dr. Professora da Universidade Estadual de Londrina. E-mail: csvjneve@uel.br 


\section{INTRODUÇÃO}

O Brasil é o maior produtor mundial de maracujá, com produção de 923 mil toneladas em área aproximada de 62.000 ha. A espécie mais representativa é Passiflora edulis Sims, maracujazeiro-azedo, com aproximadamente $95 \%$ da área plantada (IBGE, 2012). As principais demandas pelos frutos são provenientes, principalmente, da indústria de suco processado e do mercado de frutas frescas (TUPINAMABÁ et al., 2012).

A cultura do maracujazeiro no Brasil apresenta produtividade média baixa, com valores próximos a 14 t por ha ano- ${ }^{-1}$ (IBGE, 2012), em virtude de problemas fitossanitários, técnicas inadequadas de cultivo e baixa utilização de cultivares melhoradas.

O reduzido número de cultivares e híbridos comerciais disponíveis dificulta o acesso do produtor ao material propagativo de alta qualidade agronômica e limita o desenvolvimento desse setor produtivo (GONÇALVES et al., 2007; KRAUSE et al., 2012). Atualmente, para a espécie P. edulis Sims, o número de cultivares registradas é escasso, e para o Paraná não há cultivares testadas e/ou adaptadas regionalmente.

As características externas do fruto constituem os parâmetros primordiais avaliados pelos consumidores e devem atender a certos padrões para que atinjam a qualidade desejada e o valor na comercialização. Para o consumo in natura, os consumidores preferem frutos maiores, de aparência atraente, mais doces e pouco ácidos.

Os frutos destinados à indústria de suco devem apresentar, preferencialmente, alto rendimento de polpa, alto teor de sólidos solúveis totais (SST) e alta acidez total titulável (ATT). O alto teor de SST possibilita o uso de menor quantidade de polpa para elaborar o suco concentrado, e a elevada acidez garante maior flexibilidade na adição de açúcares (BRUCKNER et al., 2002).

Além destas características, a produtividade é fundamental para atender às necessidades do mercado e à remuneração dos produtores. Ortiz et al. (2012) afirmam que cada região produtora deveria desenvolver suas cultivares de maracujazeiroamarelo, satisfazendo às exigências da indústria, do produtor e do consumidor. Assim, novas cultivares podem contribuir para o aumento da produtividade e da melhoria da qualidade dos frutos fortalecendo a agroindústria regional. Gonçalves et al. (2007) citam também a importância do aprimoramento dos trabalhos de melhoramento genético nessa cultura, para favorecer a disponibilização de novas cultivares adaptadas às regiões produtoras.
O objetivo deste trabalho foi avaliar a produção e as características qualitativas dos frutos de treze híbridos de maracujazeiro-amarelo cultivados no norte do Paraná.

\section{MATERIAL E MÉTODOS}

O experimento foi realizado em pomar do Instituto Agronômico do Paraná (IAPAR), localizado em Londrina, latitude $23^{\circ} 22^{\prime} \mathrm{S}$, longitude $51^{\circ} 10^{\prime} \mathrm{W}$ e altitude de $585 \mathrm{~m}$, nas safras de 2009 e 2010 . O clima, segundo a classificação de Wilhelm Köeppen, é subtropical úmido (Cfa), com precipitação média anual de $1.500 \mathrm{~mm}$, temperatura média anual de 22,8 ${ }^{\circ} \mathrm{C}$, evapotranspiração anual de $1.350 \mathrm{~mm}$, umidade relativa anual média de $75 \%$ e insolação média de $7,14 \mathrm{~h} \mathrm{dia}^{-1}$ (IAPAR, 2014). O solo está classificado, de acordo com Santos et al. (2013), como Latossolo Vermelho distroférrico, de textura argilosa.

O delineamento experimental utilizado foi o de blocos ao acaso, com quatro repetições e uma planta por parcela. Os tratamentos constituíramse de 13 híbridos de maracujazeiro-amarelo provenientes de cruzamentos realizados com parentais selecionados de acessos do IAPAR, os quais apresentavam características agronômicas aceitáveis comercialmente. Esses parentais são originários de pomares comerciais dos Estados de São Paulo e Paraná, com plantas sem origem genética conhecida. As mudas dos híbridos foram produzidas a partir de sementes. Cada híbrido recebeu um número de identificação, variando de 65 a 77.

Para a produção das mudas, foram utilizadas sementes provenientes de frutos sadios e maduros. As mudas foram formadas em sacos plásticos individuais, com volume de $500 \mathrm{~cm}^{3}$, e mantidas em viveiro telado até o transplante. Em setembro de 2008, com cerca de 120 dias após a semeadura, as mudas foram transplantadas para o campo, com espaçamento de 6,0 $\mathrm{m}$ na linha e 4,0 $\mathrm{m}$ na entrelinha (417 plantas ha ${ }^{-1}$ ). Esse espaçamento foi utilizado com o objetivo de facilitar a avaliação das parcelas. O sistema de condução e sustentação das plantas foi em espaldeira vertical, com os mourões a uma distância de 6,0 m e um fio de arame liso a 1,8 $\mathrm{m}$ de altura em relação ao solo. As plantas foram conduzidas em haste única até o fio de arame, e os ramos secundários, orientados para única direção. Não foi feita polinização artificial e irrigação. $\mathrm{O}$ controle de plantas daninhas foi realizado por meio de roçada das entrelinhas e capina manual nas linhas.

As avaliações foram realizadas durante os ciclos de produção da cultura, que corresponderam aos períodos de abril a julho de 2009 ( $1^{\circ}$ ciclo) e 
de janeiro a julho de 2010 ( $2^{\circ}$ ciclo), por meio da coleta semanal dos frutos maduros. A produção foi determinada por meio da pesagem total dos frutos colhidos $\left(\mathrm{kg} \mathrm{planta}^{-1}\right)$ e da contagem do número de frutos por planta. Para as características qualitativas foram avaliados: massa média (g), comprimento médio $(\mathrm{mm})$, diâmetro médio $(\mathrm{mm})$, relação entre comprimento e diâmetro dos frutos, espessura média da casca $(\mathrm{mm})$, rendimento de polpa (\%), teor de sólidos solúveis totais - SST ( ${ }^{\circ}$ Brix), acidez total titulável - ATT (\%) e relação SST/ATT.

As avaliações correspondentes às características qualitativas dos frutos foram realizadas em dez frutos por parcela, colhidos aleatoriamente durante cada ciclo de produção. Os dados de comprimento, diâmetro e espessura foram obtidos com paquímetro digital, com precisão de $0,1 \mathrm{~mm}$. Para a determinação da espessura da casca, foram tomadas três medições em pontos equidistantes da casca de frutos cortados transversalmente, obtendo-se uma média por fruto.

Para a determinação do rendimento de polpa, foi calculada a porcentagem da massa da polpa, subtraindo a massa da casca em relação à massa total do fruto. O teor de SST foi obtido através de refratômetro digital com compensação automática de temperatura, e a ATT foi determinada através de titulação com $\mathrm{NaOH}$ a $0,1 \mathrm{~mol} \mathrm{~L}^{-1}$, expressa em percentagem de ácido cítrico (AOAC, 1990).

Os dados foram submetidos à análise de variância, complementada pelo teste de Tukey, a 5\% de significância. Os dados de produção e de massa média dos frutos foram comparados separadamente para cada ciclo de produção e também considerando o acumulado nos dois ciclos. As demais variáveis foram analisadas e comparadas a partir das médias dos dois ciclos. Foi realizada a transformação angular dos dados do rendimento de polpa.

\section{RESULTADOS E DISCUSSÃO}

Pode-se observar, na Tabela 1, que os 13 híbridos avaliados não apresentaram diferença significativa para a produção do $1^{\circ}$ e $2^{\circ}$ ciclos e produção acumulada. No primeiro ciclo, a produção variou de 21,3 a $28,3 \mathrm{~kg}$ de fruto por planta, e no segundo, a variação foi de $57,4 \mathrm{a} 76,3 \mathrm{~kg}$ de fruto por planta. Considerando-se a densidade populacional do maracujazeiro-amarelo no presente trabalho, estima-se que os híbridos produziram, no conjunto dos dois ciclos, de 34,5 t ha ${ }^{-1}$ (híbrido '73') a 43,6 t ha- ${ }^{1}$ (híbrido ' 66 '), valores acima da produtividade média brasileira, que é de $28 \mathrm{t} \mathrm{ha-}^{-1}$ para dois ciclos (IBGE, 2012). Os valores referentes à produção obtidos neste trabalho devem-se, em grande parte, às boas características complementares dos componentes fisiológicos da produtividade dos parentais. Incrementos expressivos na produtividade e na produção de diferentes híbridos de maracujazeiro também foram observados por Maia et al. (2009), Melo et al. (2001) e Zaccheo et al. (2012).

Quanto ao número de frutos produzidos, também se constata que não ocorreram diferenças significativas nos dois ciclos e no acumulado de produção (Tabela 1), com produção de 91,3 a 133,5 frutos por planta no primeiro ciclo e 319 a 460,5 frutos por planta no segundo ciclo. Freitas et al. (2011), avaliando o desempenho agronômico de 38 acessos e de cinco testemunhas de maracujazeiro-amarelo, no Município de Cruz das Almas - BA, observaram valores menores e variações mais expressivas para número de frutos. Naquelas condições, no $1^{\circ}$ ciclo de produção, o número de frutos produzidos variou de 14 a 115,7 frutos por planta.

Quanto à massa dos frutos, foram evidenciadas diferenças significativas entre os híbridos ' 70 ', que apresentou a maior massa média, e o híbrido '74', com menor massa média no $1^{\circ}$ ciclo. Os híbridos ' 67 ' e '70' apresentaram valores superiores para massa média de frutos, diferenciando-se apenas do híbrido '74' que apresentou o menor valor na média dos ciclos de produção (Tabela 2). Frutos com massa média acima de $180 \mathrm{~g}$ apresentam ótimo valor comercial para consumo in natura (FREITAS et al., 2011), o que foi encontrado em 11 dos 13 híbridos de maracujá-amarelo avaliados neste estudo. Meletti et al. (2000), avaliando caracteres produtivos de oito híbridos de maracujazeiro-amarelo no interior de São Paulo, observaram valores de massa de fruto que variaram de 155 a $237 \mathrm{~g}$, considerados semelhantes aos do presente trabalho e superiores àqueles encontrados por Zaccheo et al. (2012), que variaram de 130,6 a 202,3 g.

Para as características físico-químicas dos frutos (Tabelas 3 e 4), observaram-se diferenças significativas para comprimento médio do fruto, relação entre comprimento e diâmetro do fruto, rendimento de polpa, SST, ATT e relação SST/ATT. A amplitude de variação do comprimento do fruto foi de $82,1 \mathrm{~mm}$ (híbrido '74') e máximo de $92,6 \mathrm{~mm}$ (híbrido ' 72 '). Esses valores foram semelhantes aos observados por Farias et al. (2005), entre 76,2 mm e 84,2 mm, e por Zaccheo et al. (2012). Para diâmetro de fruto, a variação foi de 75,1 mm (híbrido 65) a $83,8 \mathrm{~mm}$ (híbrido 67); resultados semelhantes foram encontrados por Freitas et al. (2011) e por Meletti et al. (2003).

Para o mercado in natura, o tamanho dos 
frutos é uma característica muito valorizada pelos consumidores, já que os frutos de maior tamanho têm melhor remuneração (BRUCKNER et al., 2002). Todos os híbridos do presente trabalho produziram frutos com diâmetro maior que $55 \mathrm{~mm}$ (Tabela 3), considerado o mínimo adequado para se enquadrar na classificação comercial (MAIA et al., 2009).

A relação entre comprimento e diâmetro está relacionada ao formato do fruto, com valor igual a 1 para frutos redondos e maiores para frutos ovalados. Em maracujá, prefere-se selecionar frutos ovais, por obterem maior valor comercial e apresentarem maior rendimento de suco (MELETTI et al., 2000). Todos os híbridos avaliados apresentaram frutos ovalados, destacando-se o '72' como o mais ovalado (relação igual a 1,18). Quanto à espessura da casca, não foram constatadas diferenças significativas entre os frutos dos híbridos.

Cascas muito espessa resultam em menor rendimento de polpa, porém para o transporte essa característica torna-se uma vantagem, por aumentar a resistência física do fruto (MELETTI et al., 2000). Há necessidade de estudos para a definição de um padrão para esta característica, ainda inexistente, aliando uma cavidade interna maior com bom rendimento de polpa, sem que isto signifique maior dano físico ao fruto, devido à baixa resistência do mesocarpo (MELETTI et al., 2003).

Quanto ao rendimento médio de polpa, o híbrido '69' foi o que apresentou maior valor para esta característica, 40,1\%, embora não se tenha diferenciado dos outros, exceto do híbrido '77', que apresentou baixo rendimento. Segundo Freitas et al. (2011), os frutos de maracujazeiro-amarelo destinados à industria devem ter rendimento acima de 30\%. Neste estudo, somente o híbrido ' 77 ' teve rendimento abaixo desse valor. Menores rendimentos de polpa foram observados por Zaccheo et al. (2012) nas condições de Londrina-PR, obtendo valor máximo de 35,5\%. Porém, Negreiros et al. (2008), Pio et al. (2003), Godoy et al. (2007) e Nascimento et al. (2003), ao avaliarem diferentes genótipos, observaram valores máximos de 45,8; 58,5; 52,4 e $57,7 \%$, respectivamente.

Todos os híbridos, neste trabalho, atendem ao padrão mínimo de $13{ }^{\circ}$ Brix exigido pelas indústrias de sucos (MELETTI et al., 2000). Os híbridos apresentaram teores de SST de 13,7 (híbrido '65') a 15,4 ${ }^{\circ}$ Brix (híbrido ' $75^{\prime}$ '). Os teores de sólidos solúveis indicam a quantidade dos sólidos dissolvidos na polpa. De modo geral, altos teores de SST são desejáveis para a indústria, por consumirem menor quantidade de açúcar (CHITARRA; CHITARRA, 1990).
O teor elevado de SST é uma característica bastante desejável para a indústria e o mercado de frutos in natura, pois são necessários cerca de $11 \mathrm{~kg}$ de frutos com SST entre 11 e 12\% para a obtenção de $1 \mathrm{~kg}$ de suco concentrado a $50^{\circ}$ Brix. Assim, quanto mais alto for o teor de SST, menor a quantidade de frutos necessária para a concentração do suco (NASCIMENTO et al., 2003).

A amplitude dos dados de ATT neste trabalho foi de 3,7 (híbrido '74') a 5,0 (híbrido '71'), o que os torna excelentes opções para o uso na indústria, uma vez que o Ministério da Agricultura e do Abastecimento recomenda valor mínimo de 2,5\% de ATT no suco do maracujá (BRASIL, 2003). Farias et al. (2005) obtiveram valor médio para ATT de $4,86 \%$, no estudo para seleção de progênies de maracujazeiro-amarelo. Para Freitas et al. (2011), os valores de ATT variaram de 2,39 a 4,6\% em diferentes genótipos de maracujá-amarelo. Valores elevados de acidez no suco de maracujazeiro constituem uma característica de importância para o processamento da fruta, em virtude da possibilidade de redução da adição de acidificantes (NASCIMENTO et al., 2003), considerando-se que a acidez é um importante parâmetro na apreciação do estado de conservação de produtos alimentícios.

A relação SST/ATT é considerada uma das formas mais práticas de avaliar-se o sabor dos frutos, que no presente trabalho variou de 2,95 (híbrido '65') a 4,00 (híbrido '74') (Tabela 4). O teor de açúcar e a acidez dos frutos podem sofrer variação em decorrência de fatores ambientais e práticas de cultivo, qualidade de luz solar e temperatura, como também do tipo e dosagens de fertilizantes; portanto, com reflexos diretos na relação SST/ATT (NASCIMENTO et al., 2003). 
TABELA 1 - Produção e número de frutos por planta produzidos no $1^{\circ}$ ciclo, $2^{\circ}$ ciclo e acumulado dos dois ciclos de 13 híbridos de maracujazeiro-amarelo no norte do Paraná. Londrina-PR, 2009 e 2010.

\begin{tabular}{|c|c|c|c|c|c|c|}
\hline \multirow{2}{*}{ Híbridos } & \multicolumn{3}{|c|}{ Produção } & \multicolumn{3}{|c|}{$\mathrm{N}^{0}$ de frutos } \\
\hline & $1^{\circ}$ ciclo & $2^{\circ}$ ciclo & Acumulada & $1^{\circ}$ ciclo & $2^{\circ}$ ciclo & Acumulado \\
\hline & \multicolumn{6}{|c|}{----------------kg planta-1'----------- } \\
\hline 65 & $23,1 a^{*}$ & $74,0 \mathrm{a}$ & $97,1 \mathrm{a}$ & $121,0 \mathrm{a}$ & $460,5 \mathrm{a}$ & $581,5 \mathrm{a}$ \\
\hline 66 & $28,3 \mathrm{a}$ & $76,3 \mathrm{a}$ & $104,6 \mathrm{a}$ & $121,3 \mathrm{a}$ & $400,3 \mathrm{a}$ & $521,5 \mathrm{a}$ \\
\hline 67 & $27,3 \mathrm{a}$ & $68,9 \mathrm{a}$ & $96,1 \mathrm{a}$ & $114,0 \mathrm{a}$ & $331,0 \mathrm{a}$ & $445,0 \mathrm{a}$ \\
\hline 68 & $22,8 \mathrm{a}$ & $67,0 \mathrm{a}$ & $89,8 \mathrm{a}$ & $120,5 \mathrm{a}$ & $406,3 \mathrm{a}$ & $526,8 \mathrm{a}$ \\
\hline 69 & $23,8 \mathrm{a}$ & 64,9 a & 88,7 a & $111,3 \mathrm{a}$ & $348,0 \mathrm{a}$ & $459,3 \mathrm{a}$ \\
\hline 70 & $22,5 \mathrm{a}$ & $65,5 \mathrm{a}$ & $88,0 \mathrm{a}$ & $91,3 \mathrm{a}$ & 319,0 a & $410,3 \mathrm{a}$ \\
\hline 71 & $26,8 \mathrm{a}$ & $57,4 \mathrm{a}$ & $84,1 \mathrm{a}$ & $133,5 \mathrm{a}$ & $347,0 \mathrm{a}$ & $480,5 \mathrm{a}$ \\
\hline 72 & $25,3 \mathrm{a}$ & $69,2 \mathrm{a}$ & $94,5 \mathrm{a}$ & $115,0 \mathrm{a}$ & $399,5 \mathrm{a}$ & $514,5 \mathrm{a}$ \\
\hline 73 & $21,9 \mathrm{a}$ & $60,9 \mathrm{a}$ & $82,8 \mathrm{a}$ & $111,8 \mathrm{a}$ & $373,3 \mathrm{a}$ & $485,0 \mathrm{a}$ \\
\hline 74 & $21,4 \mathrm{a}$ & $62,6 \mathrm{a}$ & $84,0 \mathrm{a}$ & $116,8 \mathrm{a}$ & $385,0 \mathrm{a}$ & $501,8 \mathrm{a}$ \\
\hline 75 & 23,6 a & 74,6 a & 98,2 a & $110,5 \mathrm{a}$ & 446,5 a & $557,0 \mathrm{a}$ \\
\hline 76 & $23,7 \mathrm{a}$ & $72,2 \mathrm{a}$ & $96,0 \mathrm{a}$ & $111,0 \mathrm{a}$ & $417,3 \mathrm{a}$ & $528,3 \mathrm{a}$ \\
\hline 77 & $21,3 \mathrm{a}$ & $69,7 \mathrm{a}$ & $91,0 \mathrm{a}$ & $105,0 \mathrm{a}$ & $391,3 \mathrm{a}$ & $496,3 \mathrm{a}$ \\
\hline CV (\%) & 14,17 & 19,15 & 16,22 & 16,46 & 20,44 & 18,28 \\
\hline
\end{tabular}

TABELA 2 - Massa média por fruto da produção do $1^{\circ}$ ciclo, do $2^{\circ}$ ciclo e média da massa do fruto nos dois ciclos de produção de 13 híbridos de maracujazeiro-amarelo no norte do Paraná. LondrinaPR, 2009 e 2010.

\begin{tabular}{cccc}
\hline \multirow{2}{*}{ Híbridos } & \multicolumn{3}{c}{ Massa média do fruto } \\
\cline { 2 - 4 } & $\mathbf{1}^{\mathbf{a}}$ ciclo & $\mathbf{2}^{\mathbf{a}}$ ciclo & Média \\
\cline { 2 - 4 } 65 & $193,3 \mathrm{ab} *$ & $163,0 \mathrm{a}$ & $178,0 \mathrm{ab}$ \\
66 & $236,8 \mathrm{ab}$ & $191,8 \mathrm{a}$ & $214,3 \mathrm{ab}$ \\
67 & $243,5 \mathrm{ab}$ & $212,3 \mathrm{a}$ & $227,8 \mathrm{a}$ \\
68 & $199,5 \mathrm{ab}$ & $165,8 \mathrm{a}$ & $182,5 \mathrm{ab}$ \\
69 & $235,8 \mathrm{ab}$ & $187,3 \mathrm{a}$ & $211,5 \mathrm{ab}$ \\
70 & $247,3 \mathrm{a}$ & $208,0 \mathrm{a}$ & $227,8 \mathrm{a}$ \\
71 & $201,0 \mathrm{ab}$ & $166,0 \mathrm{a}$ & $183,5 \mathrm{ab}$ \\
72 & $219,5 \mathrm{ab}$ & $172,8 \mathrm{a}$ & $196,0 \mathrm{ab}$ \\
73 & $219,0 \mathrm{ab}$ & $168,0 \mathrm{a}$ & $193,8 \mathrm{ab}$ \\
74 & $183,5 \mathrm{~b}$ & $160,8 \mathrm{a}$ & $172,3 \mathrm{~b}$ \\
75 & $213,8 \mathrm{ab}$ & $164,0 \mathrm{a}$ & $188,8 \mathrm{ab}$ \\
76 & $212,5 \mathrm{ab}$ & $171,8 \mathrm{a}$ & $192,0 \mathrm{ab}$ \\
77 & $208,0 \mathrm{ab}$ & $179,8 \mathrm{a}$ & $194,0 \mathrm{ab}$ \\
\hline $\mathrm{CV}(\%)$ & 11,70 & 12,34 & 11,21 \\
\hline
\end{tabular}

*Médias seguidas da mesma letra nas colunas não diferem entre si, pelo teste de Tukey, a 5\% de significância. 
TABELA 3 - Comprimento médio, diâmetro médio, relação entre comprimento e diâmetro (C/D) e espessura média da casca dos frutos de 13 híbridos de maracujazeiro-amarelo no norte do Paraná. Londrina-PR, 2009 e 2010.

\begin{tabular}{cccccc}
\hline Híbridos & Comprimento & Diâmetro & C/D & Espessura \\
\cline { 2 - 3 } \cline { 5 - 6 } & $82,5 \mathrm{~b}^{*}$ & & $75,1 \mathrm{a}$ & $1,10 \mathrm{ab}$ & $4,4 \mathrm{a}$ \\
65 & $86,3 \mathrm{ab}$ & $80,7 \mathrm{a}$ & $1,07 \mathrm{~b}$ & $5,0 \mathrm{a}$ \\
67 & $90,1 \mathrm{ab}$ & $83,8 \mathrm{a}$ & $1,08 \mathrm{~b}$ & $4,9 \mathrm{a}$ \\
68 & $84,2 \mathrm{ab}$ & $77,5 \mathrm{a}$ & $1,09 \mathrm{~b}$ & $4,2 \mathrm{a}$ \\
69 & $88,6 \mathrm{ab}$ & $78,8 \mathrm{a}$ & $1,12 \mathrm{ab}$ & $4,2 \mathrm{a}$ \\
70 & $92,4 \mathrm{a}$ & $83,2 \mathrm{a}$ & $1,11 \mathrm{ab}$ & $4,9 \mathrm{a}$ \\
71 & $85,1 \mathrm{ab}$ & $76,5 \mathrm{a}$ & $1,12 \mathrm{ab}$ & $4,3 \mathrm{a}$ \\
72 & $92,6 \mathrm{a}$ & $78,6 \mathrm{a}$ & $1,18 \mathrm{a}$ & $4,5 \mathrm{a}$ \\
73 & $90,0 \mathrm{ab}$ & $81,4 \mathrm{a}$ & $1,11 \mathrm{ab}$ & $4,8 \mathrm{a}$ \\
74 & $82,1 \mathrm{~b}$ & $77,8 \mathrm{a}$ & $1,06 \mathrm{~b}$ & $4,9 \mathrm{a}$ \\
75 & $87,4 \mathrm{ab}$ & $79,5 \mathrm{a}$ & $1,10 \mathrm{ab}$ & $4,7 \mathrm{a}$ \\
76 & $88,3 \mathrm{ab}$ & $78,6 \mathrm{a}$ & $1,13 \mathrm{ab}$ & $5,3 \mathrm{a}$ \\
77 & $89,8 \mathrm{ab}$ & $80,6 \mathrm{a}$ & $1,12 \mathrm{ab}$ & $5,4 \mathrm{a}$ \\
\hline $\mathrm{CV}(\%)$ & 4,40 & 5,11 & 2,93 & 10,77 \\
\hline
\end{tabular}

*Médias seguidas da mesma letra nas colunas não diferem entre si, pelo teste de Tukey, a 5\% de significância.

TABELA 4 - Rendimento médio de polpa, teor de sólidos solúveis totais (SST), acidez total titulável (ATT) e relação entre o teor de sólidos solúveis totais e acidez total titulável (SST/ATT) da polpa dos frutos de 13 híbridos de maracujazeiro-amarelo no norte do Paraná. Londrina-PR, 2009 e 2010.

\begin{tabular}{|c|c|c|c|c|}
\hline Híbridos & Rendimento** & SST & ATT & SST/ATT \\
\hline & -------\%"----- & ----'Brix---- & -------\%"----- & \\
\hline 65 & $31,1 \mathrm{ab}^{*}$ & $13,7 \mathrm{~b}$ & $4,7 \mathrm{ab}$ & $2,95 \mathrm{~b}$ \\
\hline 66 & $35,9 \mathrm{ab}$ & $14,7 \mathrm{ab}$ & $4,9 \mathrm{a}$ & $3,03 \mathrm{~b}$ \\
\hline 67 & $35,4 \mathrm{ab}$ & $14,9 \mathrm{ab}$ & $4,7 \mathrm{ab}$ & $3,25 \mathrm{ab}$ \\
\hline 68 & $34,9 \mathrm{ab}$ & $13,9 \mathrm{~b}$ & $4,5 \mathrm{ab}$ & $3,13 \mathrm{ab}$ \\
\hline 69 & $40,1 \mathrm{a}$ & $15,0 \mathrm{ab}$ & $4,5 \mathrm{ab}$ & $3,33 \mathrm{ab}$ \\
\hline 70 & $33,3 \mathrm{ab}$ & $14,7 \mathrm{ab}$ & $4,7 \mathrm{ab}$ & $3,15 \mathrm{ab}$ \\
\hline 71 & $33,9 \mathrm{ab}$ & $15,0 \mathrm{ab}$ & $5,0 \mathrm{a}$ & $3,03 \mathrm{~b}$ \\
\hline 72 & $34,6 \mathrm{ab}$ & $13,8 \mathrm{~b}$ & $4,7 \mathrm{ab}$ & $2,98 \mathrm{~b}$ \\
\hline 73 & $30,4 \mathrm{ab}$ & $14,0 \mathrm{ab}$ & $4,1 \mathrm{ab}$ & $3,58 \mathrm{ab}$ \\
\hline 74 & $33,5 \mathrm{ab}$ & $14,8 \mathrm{ab}$ & $3,7 \mathrm{~b}$ & $4,00 \mathrm{a}$ \\
\hline 75 & $31,6 \mathrm{ab}$ & $15,4 \mathrm{a}$ & $4,1 \mathrm{ab}$ & $3,78 \mathrm{ab}$ \\
\hline 76 & $31,5 \mathrm{ab}$ & $14,4 \mathrm{ab}$ & $4,4 a b$ & $3,35 \mathrm{ab}$ \\
\hline 77 & $28,4 \mathrm{~b}$ & $14,1 \mathrm{ab}$ & $4,6 \mathrm{ab}$ & $3,13 \mathrm{ab}$ \\
\hline CV (\%) & 7,89 & 3,98 & 9,45 & 11,70 \\
\hline
\end{tabular}

*Médias seguidas da mesma letra nas colunas não diferem entre si, pelo teste de Tukey, a 5\% de significância.

**Dados transformados por transformação angular. 


\section{CONCLUSÕES}

O híbrido ' 72 'é considerado o mais promissor para o mercado de frutas frescas, pelo conjunto das características desejáveis, como produção, peso, tamanho e formato do fruto e qualidade da polpa.

O híbrido ' 69 ' é indicado para a indústria de suco, face às boas características industriais, apresentando também bons parâmetros de produção.

\section{REFERÊNCIAS}

AOAC - Association of Official Analytical Chemists. Offcial methods of analysis of the Association of Offcial Analytical Chemists. 15. ed. Arlington, 1990. v.1, p.685-1213.

BRASIL. Ministério da Agricultura e do Abastecimento. Instrução Normativa ${ }^{\circ} 12$, de 4 de setembro de 2003. Diário Oficial da União, Brasília, 2003. Seção1, p.72-76.

BRUCKNER, C. H.; MELETTI, L. M. M.; OTONI, W. C.; ZERBINI JÚNIOR, F. M. Maracujazeiro. In. BRUCKNER, C.H. (Ed.). Melhoramento de fruteiras tropicais. Viçosa: UFV, 2002. p.373-410.

Chitarra, M. I. F.; ChitarRa, A. B. Póscolheita de frutos e hortaliças: fisiologia e manuseio. Lavras: ESAL/FAEPE, 1990. 320 p.

FARIAS, M. A. A.; FARIA, G. A.; CUNHA, M. D.; PEIXOTO, C. P.; SOUSA, J. S. Caracterização física e química de frutos de maracujá-amarelo de ciclos de seleção massal estratificada e de populações regionais. Magistra, Cruz das Almas, v.17, p.83-87, 2005.

FREITAS, J. P. X.; DE OLIVEIRA, E. J.; DA CRUZ NETO, A. J.; DOS SANTOS, L. R. Avaliação de recursos genéticos de maracujazeiro-amarelo Pesquisa Agropecuária Brasileira, Brasília, v.46, p.1013-1020, 2011.

GODOY, R. C. B. de; LEDO, C. A. da S.; SANTOS, A. P. dos; MATOS, E. L. S.; LIMA, A. de A.; WASZCZYNSKYJ, N. Diversidade genética entre acessos de maracujazeiro- amarelo avaliada pelas características físico-químicas dos frutos. Revista Ceres, Viçosa, v.54, n. 316, p.541-547, 2007.
NETO, F. V.; PEREIRA, M. G.; PEREIRA, T. N. S. Seleção e herdabilidade na predição de ganhos genéticos em maracujá-amarelo. Pesquisa Agropecuária Brasileira, Brasília, v.42, p.193198, 2007.

IAPAR. Agrometeorologia. Cartas climáticas. Londrina: Instituto Agronômico do Paraná. 2014; Disponível em: <www.iapar.br/>. Acesso em: 20 mar. 2014.

IBGE - Instituto Brasileiro de Geografia e Estatística. 2012. Disponível em: $\leq$ http://www.sidra.ibge.gov. $\mathrm{br} / \mathrm{bda} / \mathrm{agric} /$ default.asp? $\mathrm{t}=4 \& \mathrm{z}=\mathrm{t} \& \mathrm{o}=11 \& \mathrm{u} 1=1 \&$ $\mathrm{u} 2=1 \& \mathrm{u} 3=1 \& \mathrm{u} 4=1 \& \mathrm{u} 5=1 \& \mathrm{u} 6=1>$. Acesso em: 4 dez. 2012.

KRAUSE, W.; SOUZA, R. S.; NEVES, L. G.; CARVALHO, M. L. S.; VIANA, A. P.; FALEIRO, F. G. Ganho de seleção no melhoramento genético intrapopulacional do maracujazeiro-amarelo. Pesquisa Agropecuária Brasileira, Brasília, v. 47, n. 1, p. 51-57, 2012.

MAIA, T. E. G.; PEIXOTO, J. R.; JUNQUEIRA, N. T. V.; SOUSA, M. A. F. Desempenho agronômico de genótipos de maracujazeiro-azedo cultivados no Distrito Federal. Revista Brasileira de Fruticultura, Jaboticabal, v. 31, n. 2, p. 500-506, 2009.

MELETTI, L. M. M.; BERNACCI, L. C.; SOARESSCOTT, M. D.; AZEVEDO FILHO, J. A. de; MARTINS, A. L. M. Variabilidade genética em caracteres morfológicos, agronômicos e citogenéticos de populações de maracujazeiro-doce (Passifora alata Curtis). Revista Brasileira de Fruticultura, Jaboticabal, v. 25, p. 275-278, 2003.

MELETTI, L. M. M.; SANTOS, R. R. dos; MINAMI, K. Melhoramento do maracujazeiro-amarelo: obtenção do cultivar 'composto IAC-27'. Scientia Agricola, Piracicaba, v. 57, n. 3, p. 491-498, 2000.

MELO, K. T.; MANICA, I.; JUNQUEIRA, N. T. V. Produtividade de seis cultivares de maracujazeiroazedo durante três anos em Vargem Bonita-DF. Pesquisa Agropecuária Brasileira, Brasília, v. 36, n. 9, p.1117-1125, 2001. 
NASCIMENTO, W. M. O. do; TOMÉ, A. T.; OLIVEIRA, M. do S. P. de; MÜLLER, C. H.; CARVALHO, J. E. U. de. Seleção de progênies de maracujazeiro-amarelo (Passifora edulis f. favicarpa) quanto à qualidade de frutos. Revista Brasileira de Fruticultura, Jaboticabal, v.25, n.1, p.186-188, 2003.

NEGREIROS, J. R. S.; ARAÚJO NETO, S. E.; ÁLVARES, V. S.; LIMA, V. A. L.; OLIVEIRA, T. K. Caracterização de frutos de progênies de meios-irmãos de maracujazeiro-amarelo em Rio Branco - Acre. Revista Brasileira de Fruticultura, Jaboticabal, v. 30, n. 2, p.431-437, 2008.

ORTIZ, D. C.; BOHÓRQUEZ, A.; DUQUE, M. C.; TOHME, J.; CUÉLLAR, D.; VÁSQUEZ, T. M. Evaluating purple passion fruit (Passiflora edulis Sims f. edulis) genetic variability in individuals from commercial plantations in Colombia. Genetic Resources Crop Evolution, Dordrecht, v. 59, p.1089-1099, 2012.

PIO, R.; RAMOS, J. D.; MENDONÇA, V.; GONTIJO, T. C. A.; RUFINI, J. C. M.; JUNQUEIRA K. P. Caracterização físico-química dos frutos de sete seleções de maracujazeiro-amarelo para a região de Lavras - MG. Revista Ceres, Viçosa, MG, v. 50, n. 291, p. 573-582, 2003.
SANTOS, R. D.; LEMOS, R. C.; SANTOS, H. G.; KER, J. C.; ANJOS, L. H. C.; SHIMIZU, S. H. Manual de descrição e coleta de solo no campo. 6.ed. Viçosa: Sociedade Brasileira de Ciência do Solo, Ed. Suprema Gráfica e Editora, 2013. 100p.

TUPINAMBÁ, D. D.; COSTA, A. M.; COHEN, K. O.; PAES, N. S.; FALEIRO, F. G.; CAMPOSVI, A. V. S.; SANTOSVI, A. L. B.; SILVA, K. N.; JUNQUEIRA, N. T. V. Pulp yield and mineral content of commercial hybrids of yellow passion fruits. Brazilian Journal of Food Technology, Campinas, v. 15, n. 1, p.15-20, 2012.

ZACCHEO, P. V. C.; AGUIAR, R. S.; STENZEL, N. M. C.; SERA, T; NEVES, C. S. V. J. Produção e características qualitativas dos frutos de híbridos de maracujazeiro-amarelo Revista Brasileira de Fruticultura, Jaboticabal, v. 34, n.4, p.1113-1120, 2012. 